\title{
Benzotriazole: A Versatile Synthetic Auxiliary
}

\section{Siva S Panda*}

Department of Chemistry \& Physics, Augusta University, USA

Received: 制 March 01, 2018; Published: 制 March 09, 2018

*Corresponding author: Siva S Panda, Department of Chemistry \& Physics, Augusta University, Augusta, GA 30912, USA,

Email: SIPANDA@augusta.edu

\section{Introduction}

Benzotriazole (BtH) is particularly versatile synthetic auxiliary because of its attractive properties. Benzotriazole can be easily inserted into molecules and equally can also act as a good leaving group. This molecule is a weak acid (pKa 8.2) as well as weak base $(\mathrm{pKa}<0)$ and because of this acid-base property of benzotriazole. This molecule also shows not only electron donating but also electron attracting ability, which leads to various synthetic applications. In 1980, benzotriazole was first reported as synthetic auxiliary in organic chemistry [1]. Since then benzotriazole is used in the construction of various monocyclic and bicyclic heterocyclic compounds which are difficult to prepare by other methods [2-5].

\section{Benzotriazole in heterocyclic synthesis}

Heterocycles are important class of compounds. Benzotriazole extensively used for the synthesis of various heterocycles. 1-Aza1,3-bis(triphenyl phosphoranylidene)propane synthesized from $\mathrm{N}$-((1H-benzo[d][1,2,3] triazol-1-yl)methyl)-1,1,1-triphenyl-15phosphanimine and methylene triphenyl phosphorane in presence of n-butyllithium, used as potential building block for the synthesis of heterocycles like 3H-benzo[c] azepine and 2,3-disubstituted pyrroles [6].

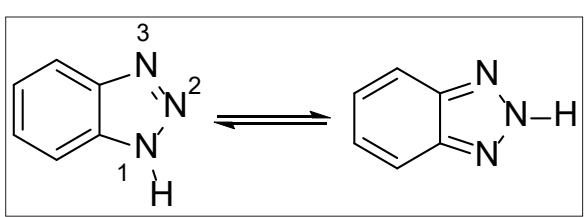

Figure 1.

2-Substituted benzothiazoles are well known for their biological properties with numerous accounts listing their synthesis [7]. Recently, benzotriazole technology was used in water as a one-pot approach to synthesize 2-peptidyl benzothiazole in excellent yield without any detectable racemization [8]. The effectiveness of this approach relies in the fact that it neither required any additional reagents nor catalyst for completion (Figure 1-3).

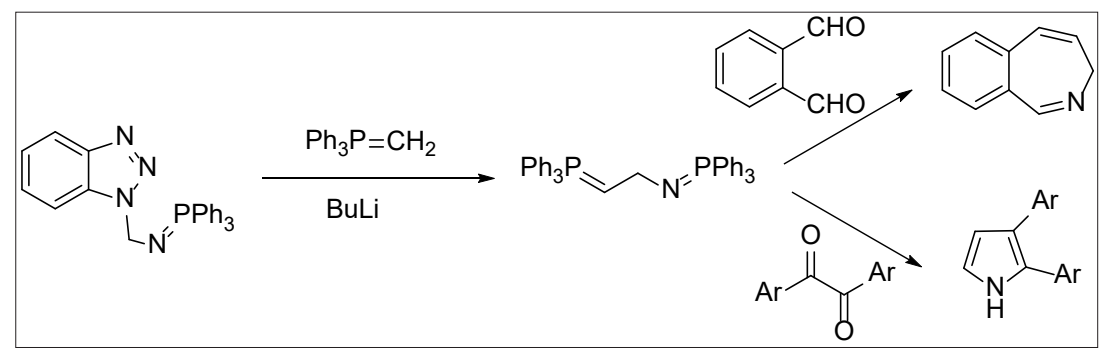

Figure 2.

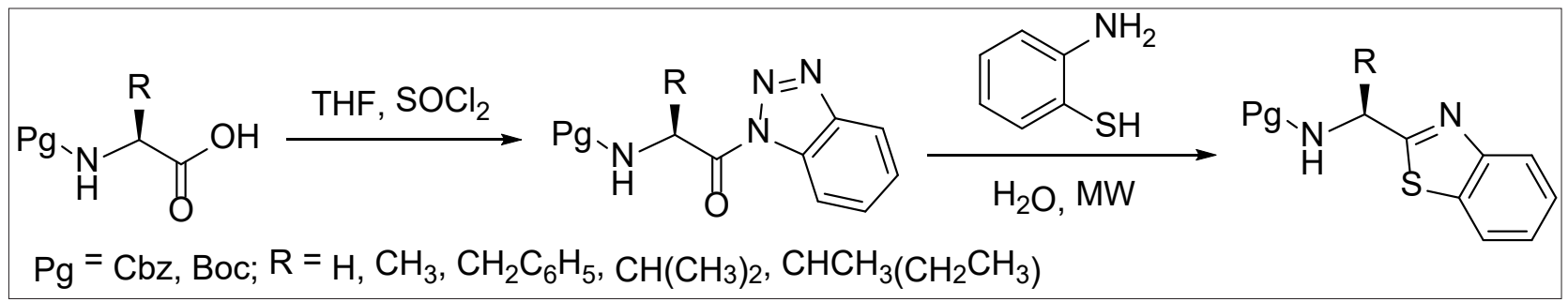

Figure 3. 


\section{Benzotriazole in Acylation, Aroylation and Substitution Reactions}

Benzotriazole and its derivatives plays important role in various reactions like acylation, aroylation and substitution reactions [2,9]. Substitution of hydroxyl group with chloride group of the sterically and electronically hindered alcohol of carbohydrates involves harsh reaction conditions and expensive reagents. Furthermore, the formation of halides from nucleofugal groups leads in the formation of unsaturated products and also chances of losing chirality due to harsh reaction condition. Saxena et. al. reported benzotriazole sulfonate (prepared in-situ from benzotriazole and thionylchloride)as potential reagent for the one pot conversion for the sterically and electronically hindered alcohol of carbohydrates into their corresponding chloride derivatives in excellent yield [9].

\section{Benzotriazole in Phosphorous Chemistry}

Organophosphorus compounds are important class of compounds. Dialkyl- and diaryl halo phosphates are generally used as building block for the synthesis of organophosphorous compounds. However these building blocks suffer from lack of stability, particularly to hydrolysis and also required toxic reagents to synthesize them. Katritzky group synthesized and demonstrated the use of 1 Hbenzo[d] [1,2,3]triazol-1-yl-1-phosphonates as a potential phosphonylation Reagents, which is quite stable than chloro derivatives [10].

\section{Benzotriazole in Peptide Synthesis}

$\mathrm{N}$-acylbenzotriazoles are superior acylating agent with various advantages over traditional acid chlorides. $\mathrm{N}$-acylbenzotriazoles are quite stable and utilized in peptide chemistry and showed better applications in compared to other peptide coupling reagents. Unprotected amino acids couple with $\mathrm{N}$-protected aminoacylbenzotriazoles in aqueous acetonitrile to deliver enantiopure dipeptides in good yield. For the synthesis of tripeptide, the carboxylic group of dipeptide is activated by benzotriazole in presence of thionylchloride followed by treatment with unprotected amino acids resulted in desired tripeptide in excellent yields. Hence, benzotriazole assisted chemistry was successfully utilized to synthesize up heptapeptides in solution phase without any detectable loss of absolute configuration [11-13].

\section{Benzotriazole in Peptidomimetic Synthesis}

Peptidomimetics are special class of compounds which are mimic to natural peptides but resistant to enzymatic hydrolysis. Several peptidomimetics like aminoxopeptides, depsipeptides, azapeptides, oxyazapeptides and hydrazine peptides were synthesized [14-18].

Benzotriazole in cyclic peptide synthesis

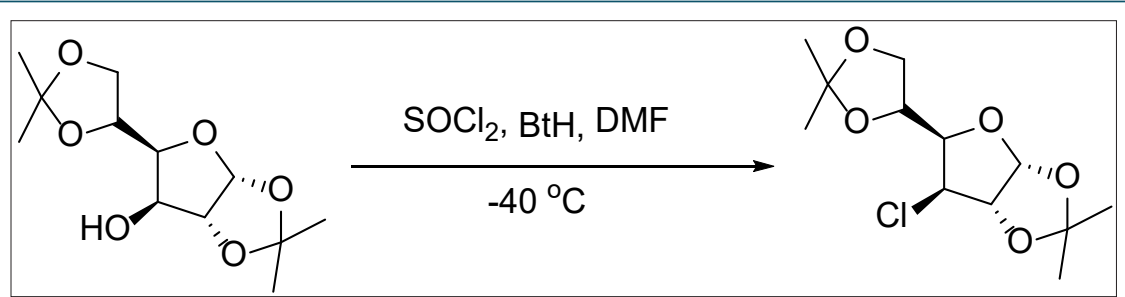

Figure 4 .

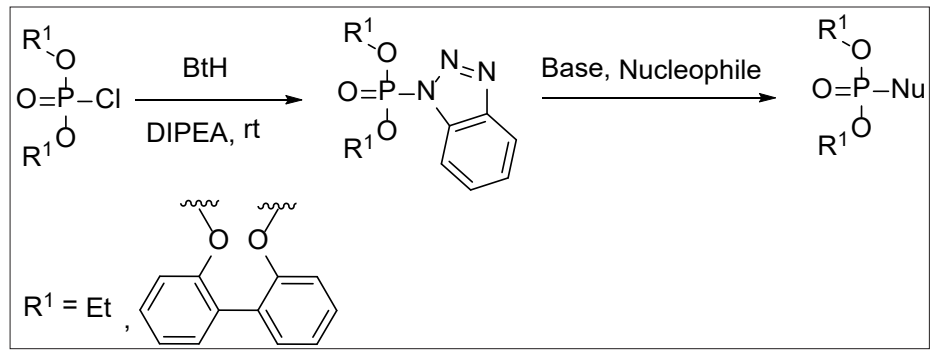

Figure 5.

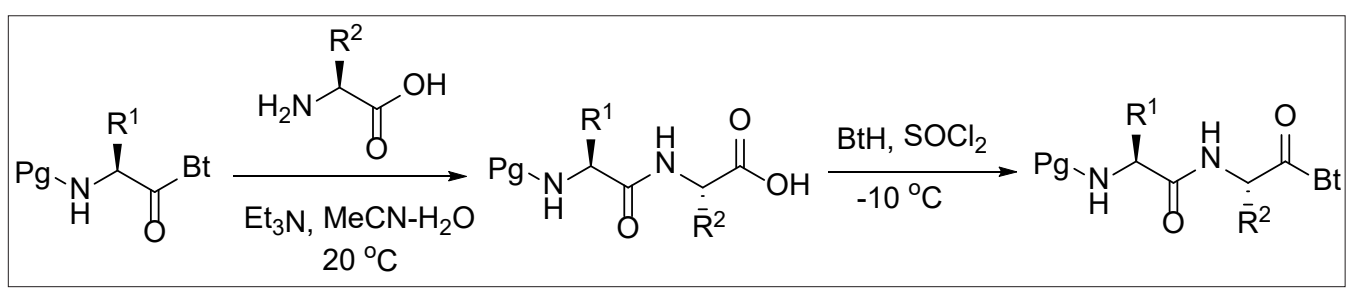

Figure 6. 
Cyclic peptides are unique class of compounds. The synthesis of cyclic peptides is often challenging. Benzotriazole methodology was extended to use in the synthesis of various cyclic peptides via dimerization macrocyclization approach [19] Figure [4-6].

N-Cbz-dipeptidoyl benzotriazolides are forced to dimerization/ cyclization to form both C2 symmetrical and unsymmetrical cyclic tetrapeptides by utilizing a Pd-assisted tandem deprotection/ cyclization reaction. However synthesis of these types of cyclicpeptides is not efficiently prepared by other reported methods [20].

\section{Conclusion}

Benzotriazole offers wide range of application as a potential synthetic auxiliary for various synthetic applications Figure 7 \& 8.

Aminoxypeptide

Figure 7.

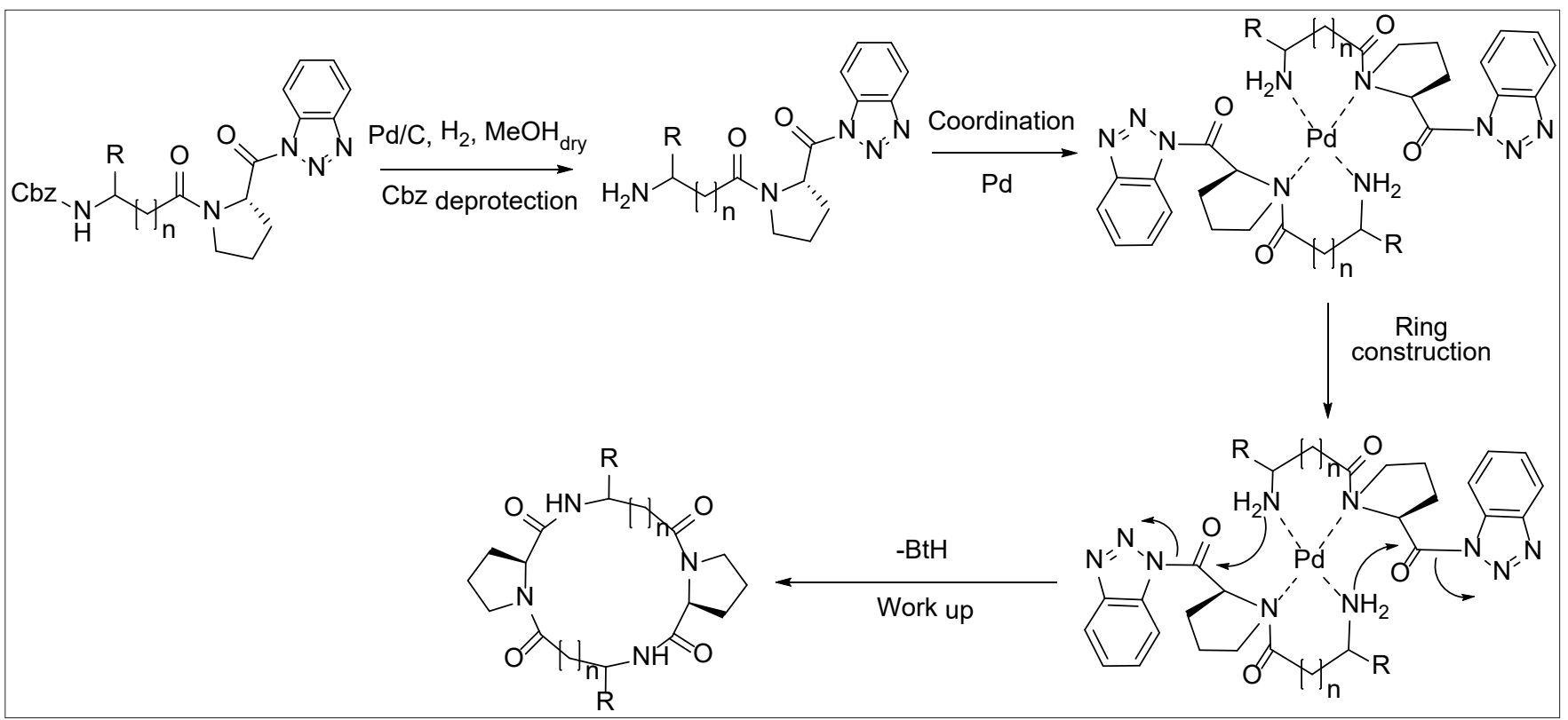

Figure 8.

\section{References}

1. Katritzky AR, Rachwal S (1987) B J Chem Soc, Perkin Trans 1: 805.

2. Hall CD, Panda SS (2016) Adv Heterocyclic Chem 1: 119.

3. Katritzky AR, Rachwal S (2010) Synthesis of heterocycles mediated by benzotriazole, Monocyclic systems. Chem Rev 110: 1564-1610.

4. Katritzky AR, Rachwal S (2011) Synthesis of Heterocycles Mediated by Benzotriazole, Bicyclic Systems Chem Rev 111: 7063-7120.

5. Zorc B, Džolić, ZR, Butula I (2012) Benzotriazole as a Synthetic Auxiliary Croat Chem ActaI 85: 595.

6. Katritzky AR, Jiang J, Steel P (1994) J J Org Chem 59: 4551.

7. Prajapati NP, Vekariya RH, Borad MA, Patel (2014) H D RSC Adv 4: 60176-60208.

8. Panda SS, Ibrahim MA, Oliferenko AA, Asiri AM, Katritzky AR, et al. (2013) Green Chem 15: 2709.

9. Azad CS, Saxena A K (2013) Tetrahedron 69: 2608.
10. Panmand DS, Tiwari AD, Panda SS, Monbaliu JCM, Beagle LK, et al. (2014) Tet Lett 55: 5898.

11. Panda SS, Hall CD, Scriven E, Katritzky AR (2013) Aldrichimica Acta 46: 43.

12. Bajaj K, Panda SS, El Nachef C, Katritzky A R (2012) Chem Bio Drug Design 80: 17.

13. Abdelmajeid A, Tala SR, Amine MS, Katritzky AR (2011) Synthesis 18: 2995.

14. Avan I, Hall CD, Katritzky AR (2014) Peptidomimetics via modifications of amino acids and peptide bonds. Chem Soc Rev 43: 3575-3594.

15. Avan I, Tala SR, Steel PJ, Katritzky AR (2011) J Org Chem 76: 4884.

16. Biswas S, AboDya NE, Oliferenko A, Khiabani A, Steel PJ, et al. (2013) J Org Chem 78: 8502.

17. AboDya N E, Biswas S, Basak A, Avan I, Alamry KA, et al. (2013) Benzotriazole-Mediated Synthesis of Aza-peptides: En Route to an AzaLeuenkephalin Analogue. J Org Chem 78: 3541. 
18. Panda SS, El Nachef C, Bajaj K, Katritzky AR (2013) Eur J Org Chem pp. 4156.

19. Ha K, Lebedyeva I, Hamedzadeh S, Li Z, Quinones R, Pillai GG (2014) R Chem Eur J 20: 4874.

\section{(c) (i) \\ This work is licensed under Creative Commons Attribution 4.0 License}

To Submit Your Article Click Here: Submit Article

DOI: $10.32474 /$ AOICS.2018.02.000129
20. White CJ, Yudin AK (2011) Contemporary strategies for peptide macrocyclization. Nat Chem 3: 509.

\section{AOICS}

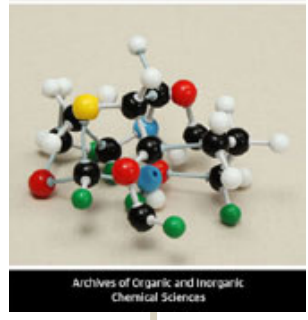

Archives of Organic and Inorganic Chemical Sciences

\section{Assets of Publishing with us}

- Global archiving of articles

- Immediate, unrestricted online access

- Rigorous Peer Review Process

- Authors Retain Copyrights

- Unique DOI for all articles 